\title{
JOVENS EMPREENDEDORES PARAIBANOS E SUAS ESTRATÉGIAS DE SOBREVIVÊNCIA
}

\author{
YOUNG ENTREPRENEURS FROM PARAIBA AND THEIR SURVIVAL STRATEGIES
}

Recebido em 21.04.2020 Aprovado em 31.07.2020

Avaliado pelo sistema double blind review

DOI: https://doi.org/10.32888/cge.v8i2.42289

\author{
Geise Kelly de Oliveira Borba \\ geisegk@hotmail.com \\ Centro Universitário de João Pessoa - UNIPÊ \\ https://orcid.org/0000-0003-2262-2970
}

\section{Lívia Nogueira Pellizzoni}

livianogueira.adm@gmaill.com

Programa UBTECH Business/Centro Universitário de João Pessoa - UNIPÊ - João Pessoa/Paraíba, Brasil https://orcid.org/0000-0001-6996-0702

\section{Resumo}

O empreendedorismo jovem apresenta-se como uma alternativa de inclusão no mercado de trabalho, sendo fator indispensável para a promoção do desenvolvimento socioeconômico brasileiro. Essa pesquisa teve por objetivo analisar as competências empreendedoras de jovens na cidade de Guarabira-PB, com base nas habilidades desenvolvidas e nas dificuldades enfrentadas por eles. Quanto à metodologia, tratou-se de pesquisa qualitativa de caráter exploratório que adotou, como técnica de coleta de dados, a realização de entrevistas semiestruturadas. Os Por meio dos resultados obtidos, observou-se que os jovens que possuem habilidades pessoais são motivados a empreender por desejarem ser donos do próprio negócio como forma de complementação da renda, em função do desemprego enfrentado.

Palavras-chave: Empreendedorismo; Jovens; Competências.

\begin{abstract}
Youth entrepreneurship presents itself as an alternative for inclusion in the labor market, being an indispensable factor for the promotion of Brazilian socioeconomic development. This research aimed to analyze the entrepreneurial skills of young people in the city of Guarabira-PB, based on the skills developed and the difficulties faced by them. As for the methodology, it was an exploratory qualitative research that adopted, as a data collection technique, semi-structured interviews. Through the results obtained, it was observed that young people who have personal skills are motivated to undertake because they want to own their own business as a way of supplementing their income, due to the unemployment faced.
\end{abstract}

Keywords: Entrepreneurship; Young; Skills. 


\section{Introdução}

O empreendedorismo exerce um papel importante na sociedade, uma vez que produz ideias inovadoras para o mercado, tendo como resultado uma maior oferta de produtos ou serviços; envolve pessoas e métodos que transformam ideias em negócios através da tomada de decisões frente aos recursos disponíveis, assumindo os riscos de uma visão futura da organização empresarial.

Segundo Drucker (2003), o empreendedor é um indivíduo capaz de demonstrar comportamento inovador para satisfazer seus clientes. Filion e Dolabela (2000) definem o empreendedor como uma pessoa que doa sua energia para a inovação e crescimento da organização de duas maneiras: criando uma empresa ou desenvolvendo algo novo preexistente. Já Custódio (2011) afirma que o empreendedor identifica oportunidades de negócios; tem a capacidade de tomar decisões; estar bem informado e avaliar as alternativas, a fim de escolher a solução mais viável. Diante do que foi exposto, o empreendedor tem a capacidade, tanto de identificar um problema e solucioná-lo, como de criar um negócio ou inovar o que já existe.

No Brasil, o empreendedorismo move a economia do país, trazendo empregos e inovações. Conforme a pesquisa do Global Entrepreneurship Monitor - GEM, a Taxa Total de Empreendedorismo (TTE) em 2017 foi de 36,4\%, evidenciando que, a cada 100 brasileiros entre 18 e 64 anos, 36 estavam iniciando alguma atividade empreendedora. Atualmente, ser o dono do próprio negócio requer algumas habilidades para alcançar o sucesso, tais como: ter conhecimento; ser um visionário; saber tomar decisões; se adequar às mudanças e a capacidade de aproveitar as oportunidades que o mercado oferece. Todo negócio precisa de um bom planejamento, conhecer os seus produtos ou serviços, assim como oferecer aos seus clientes qualidade e credibilidade.

Ainda de acordo com as pesquisas do GEM (2017), muitos jovens optam em empreender tanto devido à falta de oportunidades no mercado de trabalho, quanto por ser um meio de realização de vida. Segundo a pesquisa, 20,3\% dos novos empreendimentos identificados em 2017 foram iniciados por jovens entre 18 a 24 anos. No entanto, 5 milhões de jovens entre 18 a 34 anos que empreendem no país não são bem-sucedidos. Os jovens da faixa etária entre 25 a 34 anos somam 30,5\%, tendo mais facilidade na criação de um novo negócio, sendo proprietários ou administradores de empreendimentos na fase inicial; já os empreendedores da faixa etária entre 45 a 54 anos correspondem a 25,9\% e são donos do próprio negócio.

De acordo com o Serviço Brasileiro de Apoio às Micro e Pequenas Empresas - SEBRAE (2016) as empresas brasileiras de 2012 até 2014, têm seus dados disponíveis na Secretaria da Receita Federal - SRF com taxa de sobrevivência de até dois anos de atuação foi de 76,6\%, ou seja, a maior taxa de sobrevivência de empresas iniciais registradas no período entre 2008 a 2012; na região Nordeste, o percentual foi de 76,1\% em 2012. Conforme o ranking do Instituto Brasileiro de Geografia e Estatística - IBG), a Paraíba esteve, no ano de 2016, em 18 lugar, contando 52.775 empreendimentos, o que representa $14,8 \%$ do total.

No Estado da Paraíba, o município de Guarabira se destaca como uma das maiores cidades do Agreste por possuir um comércio diversificado que abastece as cidades circunvizinhas com produtos dos setores têxtil, calçadista, alimentício e varejista. Essa dinâmica justifica um estudo que identifique a relevância econômica da região, baseada, sobretudo, no empreendedorismo juvenil. Segundo dados do Censo Demográfico do IBGE (2010), aa cidade de Guarabira possui 55.326 habitantes, sendo a sede de uma região geoadministrativa do Estado da Paraíba composta por 24 municípios, sendo o $9^{\circ}$ maior Produto Interno Bruto (PIB) do Estado com R\$343 milhões aproximadamente. Guarabira também é a sétima cidade da Paraíba com o maior número de empresas (1.093). Suas principais atividades econômicas são baseadas na agropecuária, indústria, comércio e serviços, sendo, portanto, considerada um polo regional.

Neste sentido, a presente pesquisa teve por objetivo identificar quais são as competências empreendedoras que os jovens do município de Guarabira têm e quais são suas estratégias de sobrevivência no mercado. Diante do problema que foi exposto anteriormente, esta pesquisa irá ajudar os jovens empreendedores de Guarabira e de outras regiões a identificar aspectos que possam melhorar suas práticas profissionais como empreendedores e conhecer as competências que eles precisam adquirir, a fim de que possam entender as estratégias viáveis para os seus negócios. Este trabalho é relevante tanto para o âmbito acadêmico, quanto para o âmbito social, pois os 
resultados obtidos podem ser utilizados pelo Poder Público para o desenvolvimento de políticos voltadas ao empreendedorismo.

O trabalho está dividido em quatro seções: referencial teórico; materiais e métodos; resultados e discussões; e, ao fim, apresenta-se as considerações finais.

\section{Referencial Teórico}

Esta etapa foi dividida em três partes. Em um primeiro momento, apresenta-se a conceituação de empreendedorismo, bem como informações quanto ao seu surgimento e sua importância na economia, além das suas competências empreendedoras. Em um segundo momento, discute-se assuntos referentes aos jovens empreendedores do Brasil e suas características. Ao final, aborda-se a sobrevivência de micro e pequena empresas no cenário brasileiro.

\section{Empreendedorismo e competências empreendedoras}

O primeiro registro sobre empreendedorismo surgiu na Idade Média, onde os empreendedores eram aqueles que organizavam a empresa, pagando os empregados, bem como controlando e planejando tudo o que envolvia a organização; eles não assumiam totalmente os riscos e utilizavam recursos de terceiros, como por exemplo, recursos públicos etc. Era concedido ao profissional com habilidades de produzir, o qual contribuía para o desenvolvimento da economia (BRITO; PEREIRA; LINARD, 2013). Em 1725, a palavra "empreendedor" - do francês entrepreneur -, que significa aquele que assume riscos, foi utilizada pelo economista Richard Cantillon (CHIAVENATO, 2012).

Mesmo que na História do Brasil haja referências de grandes empreendedores, a exemplo do legado de Irineu Evangelista de Sousa, o Barão de Mauá - que iniciou diversos empreendimentos na década de 1850 (BRITO; PEREIRA; LINARD, 2013) -, nos estudos de Dornelas (2001) o termo "empreendedorismo" se popularizou no Brasil apenas na década de 1990, tendo como exemplos a atuação do Serviço Brasileiro de Apoio às Micro e Pequenas Empresas (SEBRAE), que passou a oferecer capacitação e apoio aos pequenos negócios de todo o país; e a criação da Sociedade Brasileira para Exportação de Software (SOFTEX), que teve como objetivo oferecer suporte para que as empresas exportassem softwares para o mercado internacional.

Ainda fazendo referência aos estudos de Dornelas (2015, p. 28), “o termo 'empreendedorismo' pode ser definido como o envolvimento de pessoas e processos que, em conjunto, levam à transformação de ideias em oportunidades". Assim, o "empreendedorismo" é a participação do indivíduo na sociedade, prestando serviços inovadores e transformando negócios em sucesso, no intento de atender às necessidades dos clientes, tendo características a criatividade e a inovação. Drucker (2003, p. 208) afirma que "a empresa que não inova, inevitavelmente envelhece e declina".

O Brasil é um dos países mais empreendedores do mundo segundo a pesquisa do GEM, realizada em 2016. O brasileiro tem o espírito empreendedor, acreditando que ter seu próprio negócio é uma realização dos seus sonhos, tanto pessoais quanto profissionais. Com isso, cresce o número de empresas formais e informais que geram novos postos de trabalho (ENDEAVOR, 2005). Tal expansão empreendedora é fundamental para a economia pois, como afirma Costa (2009), o Brasil depende de sua população empreendedora.

A facilidade de acesso às informações, à tecnologia e aos fatores críticos enfrentados na economia brasileira fazem com que muitos optem por procurar novas fontes de renda, sendo que a maneira mais fácil e imediata é o trabalho informal. O trabalho informal é definido por Cacciamalli (2008) como todas atividades profissionais desempenhadas sem vínculo empregatício ou formalização de empresa.

No entanto, observa-se que muitos desses negócios que surgem na informalidade apresentam dificuldades de sobrevivência no mercado em virtude do déficit educacional. Isso se evidencia, por exemplo, no estudo realizado por Endeavor (2013), o qual atesta que, das quatro maiores dificuldades enfrentadas pelo empreendedor brasileiro, três se referem à falta de conhecimento em gestão de pessoas, fluxo de caixa e gestão de negócios.

Para que o empreendimento tenha sucesso e não apresente dificuldades, é necessário fazer um bom plano de negócio que irá orientar o empreendedor a planejar de forma organizada o seu empreendimento. De acordo com o SEBRAE (2013), o plano de negócio é um documento que especifica os objetivos da organização e o que se deve fazer para atingir os objetivos planejados, eliminando os erros que são ocasionados pela falta de um processo na sua elaboração. 
Rayol (2007) reforça que o plano de negócio orienta o empreendedor nas suas decisões antes de iniciar seu empreendimento, pois aquele informará sobre o funcionamento da empresa. Embora não garanta sucesso, o plano de negócio serve principalmente para minimizar os erros e aprimorar as oportunidades. Com isso, toda empresa precisa de um planejamento para gerenciar e apresentar sua ideia para o mercado. Logo, o plano de negócio é importante, pois transmite segurança àqueles que querem iniciar um negócio ou expandir sua empresa.

O empreendedorismo no Brasil vem crescendo e se tornando cada vez mais importante na sociedade por ser uma alternativa mais segura para aqueles que querem ter seu próprio dinheiro, além de gerar um impacto no desenvolvimento socioeconômico do país. Dessa forma, cabe aos empreendedores buscar o desenvolvimento de competências empreendedoras, que, para Antonello (2005), são um conjunto de conhecimentos, habilidades e atitudes (CHA) que proporcionam ao indivíduo fixar visão, estratégias e ações na criação de seus valores (tangíveis e/ou intangíveis) para a sociedade.

Mamede e Moreira (2005) relatam que as ações que identificam as oportunidades, contribuem para a capacidade de gestão e o compromisso individual e da organização. A competência empreendedora também é desenvolvida por fatores motivacionais: independência, crescimento pessoal, necessidade de realização, além de características pessoais, como por exemplo, criatividade e inovação (JAIN, 2011).

Lizote e Verdinelli (2014) destacam que tal competência engloba diferentes personalidades, habilidades e conhecimentos. Sobre seu desenvolvimento, Lenzi (2008) defende que assim, como um indivíduo adquire suas competências, um empreendedor pode se adequar, a fim de desenvolver suas próprias competências empreendedoras. Leiria (2002) relata que as competências são fundamentais para a permanência dos empreendimentos; são características comportamentais do empreendedor, com base nas suas ações estratégicas, a partir da capacidade pessoal desse indivíduo.

As competências para Man e Lau (2000) são classificadas em seis áreas do comportamento: as competências de oportunidade, de relacionamento, conceituais, administrativas, estratégicas e de comprometimento. Elas constituem vários entendimentos sobre a perspectiva de diversos autores que serão apresentados a seguir no Quadro 01:

QUADRO 01 - Classificação das competências empreendedoras

\begin{tabular}{|c|l|c|}
\hline Classificação & \multicolumn{1}{|c|}{ Significado } & Autor \\
\hline $\begin{array}{c}\text { Competência por } \\
\text { Oportunidade }\end{array}$ & $\begin{array}{l}\text { A competência por oportunidade provém da percepção e capacidade de aperfeiçoar o } \\
\text { empreendimento ou melhorar um negócio já existente, pois garante bons desempenhos para } \\
\text { a vida da empresa. }\end{array}$ & $\begin{array}{c}\text { Hills e } \\
\text { Loforge } \\
(1996)\end{array}$ \\
\hline $\begin{array}{c}\text { Competências de } \\
\text { Relacionamento }\end{array}$ & $\begin{array}{l}\text { Refere-se aos relacionamentos pessoais do empreendedor, ou seja, é a capacidade de criar e } \\
\text { fortalecer uma boa imagem, passar confiança e possuir boa reputação, junto as redes de } \\
\text { relacionamento. }\end{array}$ & $\begin{array}{c}\text { Granovetter } \\
(1985)\end{array}$ \\
\hline $\begin{array}{c}\text { Competências } \\
\text { Conceituais }\end{array}$ & $\begin{array}{l}\text { É a capacidade de perceber situações de forma negativa e de diferentes perspectivas com o } \\
\text { intuito de encontrar soluções para o problema. O empreendedor observa as oportunidades, } \\
\text { tanto do ambiente externo, quanto do interno de uma organização, desenvolvendo etapas } \\
\text { no processo de decisão, a fim de criar ações e resolver eventuais problemas. }\end{array}$ & $\begin{array}{c}\text { Man \& Lau } \\
(2001) \\
\text { Man et al. } \\
(2000)\end{array}$ \\
\hline $\begin{array}{c}\text { Competências } \\
\text { Administrativas }\end{array}$ & $\begin{array}{l}\text { Atribui-se ao eficiente destino dos recursos físicos, tecnológicos e financeiros. Esse método } \\
\text { se estende em mecanismos de organização, motivação, delegação, controle, comando e } \\
\text { planejamento. }\end{array}$ & $\begin{array}{c}\text { Man \& Lau } \\
(2000)\end{array}$ \\
\hline $\begin{array}{c}\text { Competências } \\
\text { Estratégicas }\end{array}$ & $\begin{array}{l}\text { O empreendedor tem que ser capaz de perceber situações emergenciais no ambiente, } \\
\text { observar e entender as informações para tomar decisões e ir na direção correta. }\end{array}$ & $\begin{array}{c}\text { Mintzberg et } \\
\text { al. (2001) }\end{array}$ \\
\hline $\begin{array}{c}\text { Competências de } \\
\text { Comprometimento }\end{array}$ & $\begin{array}{l}\text { Demandam do comprometimento do empreendedor para com o negócio; ter devoção ao } \\
\text { trabalho; desejo de alcançar metas e objetivos de longo prazo, não abandonar o negócio } \\
\text { quando está em crescimento ou em crise, capacidade de recomeçar a atividade empresarial, } \\
\text { mesmo após o fracasso. }\end{array}$ & $\begin{array}{c}\text { Man e Lau } \\
(2000)\end{array}$ \\
\hline
\end{tabular}

Fonte: Elaborado pelas autoras (2019).

Entretanto, é de grande relevância que o empreendedor tenha suas competências empreendedoras para a sobrevivência dos seus empreendimentos. Com isso, o jovem brasileiro vem buscando cada vez mais seu espaço no mundo dos negócios e, para que esse desejo de empreender se torne realidade, é necessário que adquira tais competências como características pessoais, objetivando o bom desempenho de seus negócios. 


\section{Jovens empreendedores no Brasil}

Para Conceição (2017) a partir do momento que o jovem se inseri no mercado de trabalho, este estará fazendo parte do empreendedorismo jovem, sendo um fator contribuinte para o desenvolvimento socioeconômico no Brasil. O sujeito entende que, para trabalhar - quando não há alternativas de seu sustento -, é necessário abrir seu próprio negócio, ou seja, empreender.

De acordo com a Proposta de Emenda da Constituição Juvenil (PEC) aprovada pelo Congresso em setembro de 2010 e pelo Estatuto Juvenil (Lei no 12.852, 2013), é considerado jovem o cidadão que tem entre 15 e 29 anos de idade. Os jovens se adaptam às situações de risco, sempre estão conectados às tecnologias, têm o desejo de mudança e superam seus limites. Ter independência é o motivo que leva esses jovens a abrirem seu próprio negócio. Por outro lado, existem barreiras que os impedem de seguir seus sonhos, como a ausência de investimento e as sucessivas crises econômicas que o Brasil enfrentou.

A falta de capital para investir no negócio é considerado um dos fatores de bloqueio para o jovem empreender, pois ser um empreendedor e ter sucesso é um desafio diário. Além da falta de capital, o país passa por momentos de instabilidade na sua economia. A partir do ano de 2009, as taxas de crescimento do país foram reduzidas; já em 2014 ocorreu uma desaceleração em sua economia, conforme os estudos do GEM (2015).

O jovem empreendedor muitas vezes surge da falta de oportunidades no mercado de trabalho. Segundo os indicadores registrados pelo IBGE (2016), o desemprego aumentou nos últimos anos: em junho de 2015 eram 8,354 milhões de desempregados; em junho de 2016, esse número aumentou para 11,586 milhões. Logo, boa parte do desemprego deve-se a atual crise econômica do país.

Borges, Filion e Simard (2008) sugerem que o número de jovens que abrem seu próprio negócio aumente a cada ano, tendo o empreendedorismo como opção de carreira. Conforme o GEM (2015), 34\% dos jovens sonham em ter o seu próprio negócio, ficando à frente daqueles que pensam em seguir carreira nas empresas, que somam 11\%. Ser empreendedor é o desejo de muitos e é o objetivo de dois a cada três jovens brasileiros, onde a motivação parte de quatro princípios: realização de um sonho (76.4\%); ganhos financeiros (70\%); não ter chefe )64,5\%); mercado promissor (66,1\%) (FIRJAN, 2016).

O desejo de empreender pode despertar em qualquer idade, mas nos jovens tem ocorrido cada vez mais cedo, conforme Zuini (2016). Sarkar (2008, p. 241) destaca que "começar um negócio exige muita energia que, na maior parte das vezes, existe nos jovens". Esse desejo é o motivo que os levam a se destacarem no mercado e transformarem suas ideias em negócios, pois eles têm medo de falhar e por essa razão estão sempre buscando melhorar.

Conforme o estudo do sistema, a FIRJAN (2016) destacou algumas características dos jovens empreendedores, retratando que eles são: mais confiantes do que aqueles que não empreendem; gostam de fazer muitas coisas ao mesmo tempo; tentam resolver de forma rápida; importam-se com as causas sociais e ambientais; têm desejo de mudar o mundo; geralmente são mais organizados, tanto na vida pessoal como na profissional; não têm medo de correr o risco de fracassar etc. Uma vez que o sucesso de uma empresa depende do perfil do empreendedor, é de grande importância ter características que os diferencie e que faça com que a empresa seja referência no mercado.

Para incentivar os jovens a ter essas características empreendedoras de comportamento e ajudá-los a ter o seu próprio negócio a fim de que possam se manter no mercado, existem diversos programas de apoio governamentais, tais como: a Feira do Empreendedor e o Desafio SEBRAE, Semana do MEI e o Programa Jovem Empreendedor, todos ofertados pelo SEBRAE (RIBEIRO; CAMPOS, 2017). Dessa maneira, é importante que o jovem se aperfeiçoe, pois isso impacta na sobrevivência dos seus empreendimentos.

\section{Sobrevivência de micro e pequenas empresas}

Conforme pesquisa do SEBRAE (2011), no Brasil são criados mais de 1,2 milhões de novos empreendimentos formais por ano, onde mais de $99 \%$ são micro e pequenas empresas (MPE) e microempreendedores individuais (MEI). As micro e pequenas empresas são responsáveis por mais da metade dos empregos com carteira assinada no Brasil. 
Com relação ao incentivo às micro e pequenas Empresas (MPE), há uma competição entre as grandes empresas em busca de produtividade e qualidade, o que ocasionou uma isenção dos trabalhadores no mundo. Em contrapartida, dificultou-se a entrada de trabalhadores no mercado de trabalho. Por esse motivo, há uma estimulação na criação das MPE's, seja pelo desemprego ou por outros motivos (BARROS; PEREIRA, 2008). Ainda de acordo com o SEBRAE (2011, p. 04):

A sobrevivência desses empreendimentos é condição indispensável para o desenvolvimento econômico do país. Todos os estudos no Brasil e no mundo mostram que os dois primeiros anos de atividade de uma nova empresa são os mais difíceis, o que torna esse período o mais importante em termos de monitoramento da sobrevivência.

Sabendo da importância das pequenas empresas no âmbito econômico, o governo tem um papel importante no desenvolvimento social do país, sendo gerador de emprego e renda.Segundo o SEBRAE (2014), existem cerca de 9 milhões de Micro e Pequenas Empresas (MPE) no país, que representam mais da metade dos empregos formais. As MPE's são as principais geradoras de riqueza no comércio, representando 53,4\% do PIB do país. Segundo o SEBRAE (2012), essa importância socioeconômica desenvolvida pelas MPE's representa 98,5\% das empresas do país nos setores industrial, comercial e de serviços, ofertando $60 \%$ dos empregos.

As MPE's desenvolvem um papel importante na geração de trabalho por estarem em setores de serviços e comércio, onde apresentam indicadores positivos e elevam a economia do país. De acordo com Nascimento et al. (2013), é possível verificar os índices relevantes de mortalidade das MPE's realizados por vários fatores, mesmo com sua importância econômica. Por esse motivo, a necessidade de monitoramento das MPE's se torna ainda mais relevantes, pois vale identificar quais são as principais dificuldades enfrentadas pelos empreendedores e quais são os fatores que influenciam na mortalidade de seus empreendimentos.

Mahamid (2012) destaca os fatores que levam a mortalidade dos empreendimentos a partir de três aspectos: o primeiro diz respeito a administração do negócio, ou seja, o gerenciamento do empreendimento, que está ligado ao mercado e aos clientes; o segundo momento, o setor financeiro, a forma como é conduzido a gestão financeira da empresa, como é movimentado o dinheiro; e, por último a mortalidade dos aspectos externos, vinculados a economia do país, a exemplo dos juros. Mahamid (2012) ainda identificou cinco fatores que levam a falência das MPE's tais como: falta de experiência administrativa, ou seja, pouco conhecimento de gestão, marketing, custo, etc.; baixo poder de competição das empresas, fatores que afetam a competitividade; instabilidade no custo de matérias-primas dos produtos fabricados ou de serviços prestados; falta de controle na gestão de clientes e falta de critério na concessão de descontos.

Liu (2009) assenta que os problemas com taxas de tributação e falta de incentivo à política de importação contribuem para a mortalidade das MPE's. Kivrak e Arslan (2008) argumentam que as condições macroeconômicas e o governo federal influencia no fracasso dos empreendimentos.

Reis (2006) afirma que não existe uma exigência prévia para abertura de uma empresa e, dessa forma, isso proporciona um maior número de empresas sujeitas ao fracasso antes mesmo de completarem três anos de abertura. Essas empresas estão no mercado sem apresentar um índice de crescimento e, consequentemente, os empresários irão falir por não terem noção de como administrar um empreendimento.

Santini, et al. (2015) complementa que a mortalidade das empresas está relacionada a um conjunto de fatores e exemplifica os quatro principais, que são: a falta de clientes; a carga tributária elevada; a falta de capital de giro e a localização inapropriada etc. Esses fatores aumentam as chances de os empreendimentos serem malsucedidos e, consequentemente, falirem.

As MPE's têm grande importância na sociedade por ofertarem bens e serviços e fazerem com que a economia do país cresça, além da geração de emprego e renda. Como já foi mencionado, o Brasil é um país empreendedor, onde as ideias se concretizam em suas micro e pequenas empresas; portanto, é importante analisar o perfil do empreendedor e fomentar melhorias para evitar a mortalidade. 


\section{Procedimentos metodológicos}

Na primeira etapa da pesquisa foi realizado inicialmente um levantamento bibliográfico, tendo como fontes: livros, monografias e artigos científicos; pesquisas nos sítios eletrônicos do Instituto Brasileiro de Geografia e Estatística (IBGE) e do Serviço Brasileiro de Apoio e Micro e Pequenas Empresas (SEBRAE). Nesta etapa, os autores como Filion (2017, 2000, 1991), Ducker (2003), Chiavenato (2012), Man e Lau (2000), Paiva Júnior (2006, 2003) entre outros serviram de base para fundamentar o tema proposto.

Tratou-se de uma pesquisa qualitativa que, para Godoy (1995, p. 21), é caracterizada "quando o pesquisador vai a campo, buscando captar o fenômeno em estudo, a partir da perspectiva das pessoas nele envolvidas, considerando todos os aspectos de vista relevantes". De caráter exploratório, pois proporciona mais informações sobre o assunto estudado, fixando os objetivos e formulando hipóteses (PRODANOF; FREITAS, 2013).

O número de entrevistados foi dado conforme o critério de saturação dos dados (GLASER; STRAUSS, 1967), pois a partir do momento que novas entrevistas foram se tornando repetitivas, sem novas informações, optou-se por finalizar a coleta dos dados. Considerando esse critério, a saturação se deu com um total de seis empreendedores de Guarabira-PB.

As entrevistas ocorreram de forma presencial, com perguntas abertas que, para Chaer (2011) dão liberdade de resposta, podendo ser adotada a linguagem própria dos respondentes, pré-estabelecidas pela pesquisadora. Os entrevistados foram previamente escolhidos por serem popularmente conhecidos na cidade. As entrevistas ocorreram entre os meses de abril e maio de 2019, estabelecidos os horários e as datas previamente e, em seguida, dirigindo-se aos empreendimentos e às casas dos empreendedores para sua realização. As perguntas seguiram um roteiro semiestruturado, composto inicialmente por 17 perguntas (Quadro 2), dando a possibilidade de serem elaboradas novas questões de acordo com a necessidade. Tais procedimentos estão presentes na abordagem de Manzine (1991).

Conforme orientações de McCracken (1988), a entrevista teve início com perguntas mais gerais, seguidas de perguntas mais específicas de acordo com as categorias. Durante esta etapa foram feitas gravação de áudios, com a utilização de equipamento eletrônicos - que não permitem a perca das informações. Também foram preenchidas fichas de campo.

Diante das seis competências empreendedoras já apresentadas por Man e Lau (2000), foram adotadas, para servir de base nos questionamentos, mais competências adquiridas pelos jovens como a persistência, onde desenvolvem habilidades de traçar metas e objetivos, mesmo diante dos obstáculos. Ter planejamento e monitoramento sistemático, planejam tarefas, dividindo as de maior relevância para as menores com prazos definidos e revisam as metas, tomando como base as informações sobre o desempenho e as novas circunstâncias.

As categorias foram estabelecidas previamente, tendo por base as competências empreendedoras apresentadas por Man e Lau (2000). Foram elaboradas perguntas com base em cada uma das categorias relacionadas às competências: oportunidade; relacionamento; conceituais; administrativas; estratégicas e de comprometimento. Além disso, incluiu-se uma categoria relacionada aos fatores externos que influenciam na sobrevivência de pequenas empresas como Mahamid (2012) relata. Somou-se a isso perguntas sociodemográficas relativas à idade, nível de escolaridade e área de atuação, bem como as motivações iniciais para empreender. A seguir o Quadro 02 com o roteiro de perguntas:

Quadro 02: Roteiro para entrevista semiestruturada

\begin{tabular}{|c|l|}
\hline CATEGORIAS & \multicolumn{1}{|c|}{ PERGUNTAS } \\
\hline \multirow{2}{*}{ Oportunidade } & $\begin{array}{l}\text { 1- Como você identifica novas oportunidades? } \\
\text { 2- Você já vivenciou uma situação que lhe obrigou a mudar seus produtos ou serviços de forma repentina? } \\
\text { Como se saiu? }\end{array}$ \\
\hline \multirow{2}{*}{ Relacionamento } & $\begin{array}{l}\text { 3- Conte um exemplo como organiza suas prioridades pessoais para que, não interfira no bom desempenho do } \\
\text { seu empreendimento. } \\
\text { 4- Você passa uma boa imagem para os seus clientes? Cite alguns de seus comportamentos para obter confiança. }\end{array}$ \\
\hline Conceituais & $\begin{array}{l}\text { 5- Como desenvolve estratégias para se manter no mercado? Cite exemplos de estratégias utilizadas? } \\
\text { 6- Descreva uma situação a qual precisou resolver vários problemas importantes naquele dia. Como se organizou } \\
\text { para isso? }\end{array}$ \\
\hline & 7- Fale sobre uma situação em que você não tinha recursos financeiros para realizar uma tarefa. O que fez? \\
\hline
\end{tabular}

ISSN 2318-9231

CGE | Rio de Janeiro | v. 8 | n. 2 | mai. - ago. 2020 


\begin{tabular}{|c|l|}
\hline \multirow{2}{*}{ Administrativa } & $\begin{array}{l}\text { 8- Você faz uso das tecnologias? Como você lida com elas e qual a importância no seu empreendimento? } \\
\text { 9- Quais ferramentas gerenciais você utiliza para fazer a gestão do seu negócio? }\end{array}$ \\
\hline Estratégicas & $\begin{array}{l}\text { 10- Como reage às mudanças? Dê um exemplo específico. } \\
\text { 11- Quais estratégias você utiliza para inovar no seu negócio? }\end{array}$ \\
\hline \multirow{3}{*}{ Comprometimento } & $\begin{array}{l}\text { 12- Qual foi seu último projeto ou objetivo que realizou? Como alcançou? } \\
\text { 13- Consegue identificar os resultados das suas metas? E como estabelece o plano de ação para atingir? }\end{array}$ \\
\hline \multirow{3}{*}{ Aspectos externos } & $\begin{array}{l}\text { 14- Come você faz para atrair seus clientes? Dê exemplo(s). } \\
\text { 16- Você já teve algum fornecedor difícil com quem teve de lidar? Como contornou a situação? } \\
\text { 17- Com relação a sua concorrência, você a conhece? Como lida para se manter no mercado, sabendo que este é } \\
\text { muito competitivo? }\end{array}$ \\
\hline
\end{tabular}

Fonte: Elaborado pelas autoras (2019).

Para a análise e interpretação das informações, utilizou-se a técnica de análise de discurso, seguindo as orientações de Bardin (1977). Logo, buscou-se interpretar os dados no intuito de compreender as motivações e as dificuldades dos jovens quando iniciam um empreendimento na cidade de Guarabira-PB.

\section{Apresentação e análise dos resultados}

Os resultados aqui apresentados são oriundos das competências dos jovens empreendedores em seus empreendimentos, onde, com determinação, conseguem se manter ativos em atividades que possibilitam a permanência no mercado de trabalho.

\section{Perfil dos respondentes}

Todos os entrevistados são residentes da cidade em estudo, possuem idades entre 24 e 29 anos e são dos sexos masculino e feminino. Quatro dentre os seis participantes da pesquisa têm nível superior e dois deles possuem o Ensino Médio completo, os quais são donos de seus próprios negócios como mostra a seguir, no Quadro 03.

Quadro 03 - Perfil dos respondentes

\begin{tabular}{|c|c|c|c|c|c|}
\hline $\begin{array}{c}\text { Cidade onde } \\
\text { mora }\end{array}$ & Escolaridade & Idade & Entrevistado & Área de atuação & Formação \\
\hline Guarabira-PB & Nível Superior & 28 anos & Entrevistada 01 & Maquiadora & Designer de Moda \\
\hline Guarabira-PB & Nível Superior & 25 anos & Entrevistada 02 & Vendedora de maquiagem & Administração \\
\hline Guarabira-PB & Nível Superior & 24 anos & Entrevistada 03 & $\begin{array}{c}\text { Vendedora de maquiagem e } \\
\text { Joias }\end{array}$ & Gestão Comercial \\
\hline Guarabira-PB & $\begin{array}{c}\text { Ensino Médio } \\
\text { Completo }\end{array}$ & 29 anos & Entrevistado 04 & Dono de Serigrafia & - \\
\hline Guarabira-PB & Nível Superior & 29 anos & Entrevistada 05 & $\begin{array}{c}\text { Dona de escritório de } \\
\text { contabilidade e professora }\end{array}$ & Contabilidade \\
\hline Guarabira-PB & $\begin{array}{c}\text { Ensino Médio } \\
\text { Completo }\end{array}$ & 26 anos & Entrevistada 06 & Dona de Lanchonete & - \\
\hline
\end{tabular}

Fonte: Dados da pesquisa (2019).

\section{Oportunidade}

Com relação ao questionamento 01, que trata da identificação de oportunidades para empreender, cinco dos entrevistados relataram que analisam primeiro o mercado e o meio em que convivem para identificar novas oportunidades de crescimento em seus empreendimentos, sobretudo as necessidades dos seus clientes para melhor atendê-los. Isso se verifica em uma das falas:

"Pra você identificar novas oportunidades, varia bastante, você tem que tá de olho no mercado. O mercado muda e de acordo com que vai mudando, eu vou observando e identificando melhorias, sempre tendo minhas clientes como prioridade. Em relação ao que elas querem, as coisas que elas desejam adquirir e a partir disso, eu vou prestando atenção, tanto no mercado, quanto nas clientes aí eu consigo observar novas oportunidades de crescimento" (Entrevistada 03). 
No questionamento 02 , relacionado às situações que lhes obrigaram a mudar seus produtos ou serviços de forma repentina, os respondentes declararam opiniões diversas: alguns relataram que não fazem pedidos de produtos sem antes conhecer e testar, enquanto outros disseram que ainda não mudaram seus produtos ou um produto específico. Porém, a forma de abordar seus clientes muda, quando as mercadorias não correspondem de forma positiva, como relatam:

"Não aconteceu, sempre compro marcas renomadas e testo em mim os produtos, antes de usar nas minhas clientes" (Entrevistada 01).

"Produtos não, mas a forma de atender, na abordagem, sim" (Entrevistada 02).

"Sim, mudei por um que tivesse mais aceitação e esse que mudei teve aceitação rápida que o outro não estava tendo" (Entrevistado 04).

No que se refere às competências por oportunidade, identificadas por Hills e Loforge (1996), em que o indivíduo tem a percepção de desenvolver melhorias para o empreendimento e estar preparado para identificar condições favoráveis aos objetivos da organização. Partindo desse pressuposto, boa parte dos entrevistados conseguem desenvolver melhorias, relatando que fazem uma análise do mercado antes de apresentarem mudanças e que aplicam o que há de novo para atender às necessidades dos clientes, incluindo o processo competitivo. Porém, uma parcela dos respondentes não consegue obter a mesma funcionalidade de implementar melhorias para almejar seus resultados, o que implicaria no bom desenvolvimento de seus negócios.

O empreendedor é considerado o executor de inovações, sendo o responsável por buscar e guiar a inovação (ANDRADE; LIMA; BORGES, 2014). Dessa forma, é de extrema importância que ele faça tais inovações para agregar valor à sua empresa. No entanto, parte dos respondentes se limitam apenas aos mesmos produtos, embora percebam que é imprescindível inovar, ao passo que as exigências dos consumidores vão seguindo as tendências de mercado e, consequentemente, acabam não trazendo inovações para seus empreendimentos, acarretando na perda dos clientes e valor econômico, muitas vezes levando a empresa à falência.

\section{Relacionamento}

Em relação à maneira pela qual os jovens se organizam em suas prioridades pessoais para que estas não interfiram no bom desempenho de seus empreendimentos, a maioria dos entrevistados argumentou priorizar o trabalho e que tentam não misturá-lo com a vida pessoal, sendo uma tarefa bem "complicada" como os mesmos relataram. No entanto, alguns disseram não saber lidar muito bem com essa situação:

"A vida pessoal às vezes nos trava e nos deixa sem ação nos nossos afazeres, mas eu procuro não misturar, pois interfere de forma negativa no meu negócio" (Entrevistado 06).

"Eu não sei fazer isso muito bem, mas tento planejar. Existe uma coisa chamada cronograma que você estabelece as prioridades. Você vai fazendo as atividades que são mais importantes, aí se sobrar tempo, você vai terminar o que faltou no outro dia. Outra estratégia que faço é delegar funções, ou seja, eu atribuo funções” (Entrevistada 02).

Em relação à questão de os empreendedores passarem uma boa imagem aos seus clientes, todos os entrevistados responderam afirmativamente. Nesse sentido, um dos comportamentos que alguns compartilham é a aparência no modo de se vestirem e a forma de atendê-los. Os entrevistados costumam demonstrar um sorriso no rosto e ter o conhecimento do produto para estarem aptos a responder eventuais dúvidas dos seus clientes, como mencionam:

"Muitas das vezes no atendimento, a gente vai até o cliente. Como hoje o mercado é muito competitivo, quando eu vejo que o cliente tá muito interessado nos meus produtos, nos meus serviços, eu faço questão de ir pessoalmente atender cada um deles" (Entrevistado 04).

"É mostrar que você sabe daquele produto. Uma das coisas que eu procuro muito é me especializar, procurar saber, ter informação e quando você confia no produto, quando você sabe que o produto é bom, você passa essa imagem pro cliente" (Entrevistada 03). 
Ring e Van de Ven (1994) afirmam que o relacionamento é uma ação indispensável para o desenvolvimento profissional, onde o empreendedor tem que ter a capacidade de criar e fortalecer uma boa imagem, ter uma boa reputação, passar confiança, ter comprometimento e compromisso junto às redes de relacionamentos. Dessa forma, observa-se que todos os jovens demonstram ter esse relacionamento para com seus clientes, buscando aparentar que são pessoas preocupadas com a autoimagem, a forma de se vestir e de falar, que são prestativos e que estão aptos a responderem perguntas e dúvidas, além de uma boa educação.

A maioria consegue organizar um tempo para resolver tanto os problemas pessoais quanto do empreendimento, porém, há os que falham e que não tem o hábito de gerenciar seu tempo, justamente por não ter planejamento diário e não fazerem uso de ferramentas para auxiliá-los. Gerir o tempo é fundamental, tanto nas empresas, quanto na vida pessoal, e como parte deles não têm esse controle, isso desemboca em uma desorganização de funções, que vão sendo acumuladas para o dia seguinte.

\section{Competências Conceituais}

No desenvolvimento das estratégias para se manterem no mercado, alguns disseram que divulgam os seus produtos pelas redes sociais, a exemplo do Instagram, onde eles desenvolvem estratégias para socializar e interagir com o público. Além das redes sociais, o carisma é um ponto primordial; ficam atentos aos seus concorrentes, observam as estratégias dos mesmos e fazem da fraqueza deles o seu diferencial. Outros justificam que a busca do conhecimento é o que sobressai nos seus negócios, além da criação de novos produtos como os mesmos explicam:

"Busca de conhecimento, nunca parar. O conhecimento é constante, então, a gente tá sempre em busca, tanto de cursos de aperfeiçoamento, como fazendo reuniões pra gente levantar os pontos em que tem que melhorar" (Entrevistada 05).

“Tem que tá de olho no mercado. Não sou a única que vende e também não vou ser a última, então, o que é que eu faço? Eu olho meus concorrentes, olho empresas maiores que a minha e é através disso, do que elas estão fazendo, suas estratégias e transfiro pra minha realidade" (Entrevistada 03).

Em situações em que os empreendedores tiveram que resolver vários problemas no mesmo dia e como se organizam, os entrevistados relataram que anotam o que precisam resolver, priorizando os assuntos mais urgentes; caso não tiveram tempo suficiente no referido dia, deixam para o dia seguinte, como se percebe em suas falas:

"É um dos meus déficits. Existe uma coisa que é mais prioridade do que as demais. Faço uma lista com todas as urgências que eu tenho no dia, se não der tempo de resolver tudo, eu deixo pra o outro dia" (Entrevistada 05).

"É bem desafiador, mas apesar do dia ser bem cansativo, graças a Deus sempre dá certo. Então pra mim a prioridade é sempre os mais complexos, não espero pra depois. Surgiu problema, analiso e resolvo" (Entrevistado 04).

De acordo com os estudos de Dornelas (2007), as competências conceituais consubstanciam-se na capacidade de perceber situações de risco que venham a trazer problemas, com o intuito de resolvê-las. No entanto, observou-se que alguns entrevistados conseguem se manter no mercado através das redes sociais, além de investir em qualificação pessoal, buscando aprender sobre o seu negócio, acompanhando as redes sociais, a fim de socializar e interagir, fidelizando seus clientes.

No que diz respeito à questão da solução dos problemas do dia a dia, parte dos entrevistados conseguem resolvêlos, pois anotam, fazem pesquisas e têm o auxílio de ferramentas como o Excel e o Word, embora não seja a forma mais adequada, uma vez que existem alternativas mais eficazes. Todos fazem uma lista diária e priorizam aquelas com grau de importância; no caso de o tempo não ser suficiente, os entrevistados deixam a solução dos problemas remanescentes para o dia seguinte. Percebe-se também que há uma falta de autodisciplina e de administração do seu tempo, justamente por não haver um gerenciamento de suas rotinas no trabalho. Mamede e Moreira (2005) recomendam a identificação de oportunidades, o que contribuirá para a capacidade de gestão e o compromisso individual e de organização. Com isso, os autores indicam um plano de melhorias e o uso de ferramentas adequadas para auxiliar os empreendedores, a exemplo do Trello, que é um aplicativo de gerenciamento de projetos e que 
auxilia na organização dos compromissos. Com isso, observa-se que os entrevistados não possuem e nem buscam adquirir tais competências.

\section{Competências Administrativas}

Os entrevistados relataram que não têm recursos financeiros para realizarem certas tarefas e que pedem dinheiro emprestado com pessoas de confiança; quando não conseguem, esperam ter dinheiro para poder realizá-las. Poucos pedem recursos aos bancos, como apresentaram as seguintes declarações:

"Eu tenho uma pessoa de confiança pra pedir emprestado. Tudo que você faz no seu empreendimento é um investimento, às vezes dá certo, às vezes não, mas tem que tá preparado pra isso. Ter um fluxo de caixa bom pra quando acontecer eventuais problemas, ter aquele dinheiro" (Entrevistada 03).

"Hoje em dia a gente trabalha muito com parcerias e essas parcerias já vêm da divulgação. Por exemplo, eu compro muito em uma loja, aí eu faço a divulgação dela e muitas das vezes a gente ganha produtos em relação a isso. Eu tenho crédito no comércio" (Entrevistada 01).

O uso das tecnologias para eles é de extrema importância, pois favoreceria a interação entre o cliente e os empreendimentos. Muitos se justificam que separam as redes sociais pessoais e as dos seus empreendimentos, mas há os que não sabem desenvolver estratégias nas redes sociais para os seus negócios:

"Eu acho importante, mas eu não sei das estratégias que os grandes empreendimentos usam, não tenho alguém pra fazer isso pra mim, mas eu sempre dou um jeitinho de atrair meus clientes pelo Instagram" (Entrevistada 06).

"Uma empresa que não faz uso da tecnologia é uma empresa perdida hoje em dia. Tem que ter tecnologia pra fazer pedido, fechar pedido, resolver problemas com clientes, pra fechar uma venda, marcar encontro com cliente. Não tenho como fazer vendas sem a tecnologia" (Entrevistada 03).

Observou-se que os empreendedores não utilizam ferramentas gerenciais para gerir seus empreendimentos pois preferem as formas mais simples que, para eles, são eficazes, a exemplo das planilhas do Excel, que organizam suas finanças e tarefas etc. Os entrevistados disseram que não dispensam o lápis e o papel, por terem mais acesso e ser de fácil manuseio:

"Eu não tenho nada pra gerir meu negócio. É um erro meu. Eu não sei quanto eu gasto, quanto eu ganho. É algo que tenho que ter quando eu abrir meu espaço. Só uso a minha mente mesmo" (Entrevistada 01).

"Eu tenho tudo em planilhas pra organizar minhas vendas, minhas encomendas. Eu mesmo que faço. Tenho uma agenda pra meus compromissos, sou muito organizada com relação a isso" (Entrevistada 06).

Man e Lau (2000) consideram as competências administrativas como recursos físicos, tecnológicos e financeiros de uma organização. Porém observou-se que os entrevistados não buscam desenvolver essas competências, principalmente no que diz respeito aos controles financeiros, uma vez que apenas dois dos entrevistados têm fluxo de caixa devido às experiências que já tiveram, onde os erros cometidos fizeram com que eles colocassem esse fator como uma das prioridades de crescimento dos seus negócios. Os demais entrevistados não possuem pois não conseguem identificar o lucro, tampouco quantificar valor para investimento, gastando de forma desmedida, o que pode acarretar falência no futuro.

De acordo com os resultados de pesquisa de Mohamid (2012), os fatores de mortalidade estão vinculados com a forma de administrar o negócio e a economia global. Porém, no caso desta pesquisa, é voltada à nível local; a experiência administrativa; instabilidade no custo de matéria-prima dos produtos e o marketing.

Para a administração de seus empreendimentos, precisam determinar a missão, visão e valores, planejar suas ações, organizar as atividades e direcionar os processos, com o objetivo de ampliar a capacidade administrativa, de acordo com Mahamid (2012). O sucesso de um empreendimento depende da capacidade de administrar seus recursos 
financeiros, no intento de garantir tanto o capital de giro, quanto de ter um bom fluxo de caixa para que, quando surgirem eventuais mudanças, eles possam estar com recursos para a devida resolução. Quanto ao marketing, identificou-se que se limitam apenas às redes sociais como a melhor forma de expor os seus produtos ou serviços, além de inovações tecnológicas.

\section{Competências Estratégicas}

Em relação ao questionamento de como eles reagem às mudanças, alguns conseguem lidar muito bem, usam as mudanças até a seu favor. Outros entrevistados, porém, não tem tanta habilidade, mas procuram sempre manter a calma para conseguir vencer seus limites.

"Mudança é bom, mas dá medo, porque quando surge uma mudança, você nem sempre tá preparado. Tem que ter calma e pensar a melhor estratégia pra mudança" (Entrevistada 03).

"Primeiro eu me estresso, aí depois que passa a adrenalina eu vou pensar na solução do problema. Uma vez eu não tava conseguindo vender um produto que precisava ser vendido, até por ele ser bom e eu tive que mudar a estratégia de venda" (Entrevistada $02)$.

Quanto aos meios de inovação do negócio, observou-se que os entrevistados fazem, em primeiro lugar, o uso das redes sociais como fontes de pesquisa, inspiração e divulgação. Nesse sentido, afirmam que procuram analisar as falhas em seus empreendimentos para poder consertar.

"Eu vejo o que precisa ser mudado aí vou pesquisar na internet ou em livros ou vendo exemplos de outros empreendimentos, anoto e implemento. Uma dessas estratégias é no Instagram" (Entrevistada 06).

"Eu monto as estratégias de acordo com minha necessidade e adapto a realidade e assim vou conseguindo inovar. Também faço uso das redes sociais. Sempre com vídeos, forma de abordagem, fotos e mostrando os novos produtos para meus clientes" (Entrevistada 02).

Mintzberg et al. (2001) afirmam que o empreendedor tem que ser capaz de perceber situações emergenciais e tomar a melhor decisão para solucionar o problema. Logo, os entrevistados disseram que reagem às mudanças, uns que não estão preparados e outros sim; porém, é quase impossível estar preparado para eventuais mudanças atípicas, pois isso tira o empreendedor da zona de conforto e sempre vem acompanhada de algo novo ou desconhecido.

Vive-se em um momento onde os sujeitos são "alvos" de mudanças e saber resolvê-las é essencial para a sobrevivência de um empreendimento. O que deve ser feito é analisar o cenário e o que já foi colocado em prática, a fim de saber quais foram os pontos negativos e os que precisam de ajustes para que a mudança seja concluída. Criar um mecanismo de comunicação vai ajudar a difundir as informações, além de fazer uma pesquisa para traçar um caminho a ser seguido.

Constatou-se que alguns deles não adquiriram características das competências estratégicas pois não inovam, e acabam por comprar os mesmos produtos; às vezes mudam uma marca, mas não têm ideias novas para alavancar seus empreendimentos, uma vez que o consumidor é atraído pelo "novo", além de um espaço confortável e de um bom atendimento. O que se percebeu na cidade de Guarabira foi que há uma repetição de ideias, ou seja, os empreendedores reproduzem o que já tem e não se diferenciam dos demais concorrentes, acarretando sempre em empreendimentos semelhantes, sem nenhum diferencial.

\section{Competências de Comprometimento}

No que diz respeito aos projetos ou objetivos que já realizaram, as conquistas relatadas pelos entrevistados estão relacionadas às aquisições pessoais, como por exemplo, a casa própria, bem como o posicionamento do negócio na sua área de atuação com perspectivas futuras de melhorar seus empreendimentos. 
"Meu sonho era ter minha casa própria. Eu consegui com muita luta. Consegui até abrir meu negócio na minha. Isso sem dúvidas foi minha maior realização pessoal" (Entrevistada 06).

"Foi quando conquistei a margem no Instagram. Quando a gente atingiu o número que a gente desejava, aquilo ali foi uma festa, alcançamos o nosso objetivo" (Entrevistada $03)$.

De acordo com o questionamento de os empreendedores conseguirem identificar o resultado de suas metas e de estabelecerem o plano de ação para atingir, todos os entrevistados responderam "sim", pois conseguem identificar as metas dos seus planos.

"Hoje eu consigo a meta dos planos que eu fiz e estão 100\%. Às vezes quando ficava no vermelho eu não sabia qual o real motivo, mas hoje eu consigo tranquilamente. Sem dúvidas e o Word me ajuda a traçar essas metas e não me fazer esquecer" (Entrevistado 04).

"A gente tem metas e objetivos. Eu gosto muito de anotar minhas metas, porque me direciona e me mantem no foco. Coloco na parede. O que me torna capaz de conseguir alcançar o sucesso é meu foco, minha disciplina” (Entrevistada 03).

Man e Lau (2000) afirmam que o empreendedor tem que ter o desejo de alcançar suas metas e objetivos. Politis (2005) reforça que isso é um processo contínuo que facilita no desenvolvimento do conhecimento dos negócios. Portanto, quando questionados sobre seu último projeto ou objetivo realizado, poucos entrevistados responderam algo construtivo para o seu empreendimento, mas sim a conquista pessoal. No entanto, alguns entrevistados revelaram ter o desejo de ampliar seus conhecimentos ou, até mesmo, abrir o próprio espaço.

Em relação às metas, alguns entrevistados relataram que as conhece, pois as anotam, mas não fazem uso do plano de ação para conseguir. Para que um negócio seja bem-sucedido, precisa ter um bom planejamento. No entanto, para elaborar um plano de ação, necessita-se de conhecimento sobre o assunto, o que contribuirá na obtenção de uma boa coleta e análise de dados para projetar o futuro do empreendimento.

\section{Aspectos externos que influenciam na sobrevivência}

Em relação ao questionamento sobre como atraem a clientela, os entrevistados apostam na divulgação dos seus negócios por meio das redes sociais ou do rádio. Além disso, eles procuram ofertar novos produtos e estão sempre na busca pelo conhecimento para poder passar confiança aos seus clientes.

"Produto de boa qualidade e novidades, os clientes gostam de novidades. Uma consultoria, onde eu procuro me especializar para obter o máximo de informações sobre o produto, isso ajuda muito" (Entrevistada 03).

No que diz respeito a uma situação em que os empreendedores tiveram que reverter uma má impressão dos clientes para com a empresa, os entrevistados revelaram que conseguiram se sobressair, contornando a situação com bom atendimento. Isso se explica em suas falas:

"O cliente esperava mais de um serviço nosso, mas eu consegui reverter. Eu expliquei e ele entendeu que a culpa não foi minha e sim do setor administrativo que não tinha repassado a informação" (Entrevistada 05).

Com relação às dificuldades que tiveram com seus fornecedores, a maioria dos entrevistados respondeu não teve. Aqueles que tiveram alguma dificuldade afirmaram resolver tais problemas sem maiores danos para o negócio.

"Nunca tive um fornecedor complicado. Todos que eu tive, quando eu precisava, eles sempre estavam dispostos" (Entrevistada 03).

Quando questionados sobre o conhecimento em relação aos concorrentes, os entrevistados sinalizaram positivamente. No entanto, suas respostas relataram forte competitividade no mercado local. 
"Sim, sim. Hoje eu costumo dizer que não tenho concorrente, tenho incentivadores. Eles me incentivam. Quanto mais eles fazem, mas me incentivam a fazer mais e melhor" (Entrevistado 04).

A maioria relatou que atraem seus clientes com divulgações apenas nas redes sociais, considerando ser a forma mais eficaz para eles, mas não têm o conhecimento em marketing para administrar e, assim, impulsionar suas vendas. O que se pode observar nos relatos é que as redes sociais se tornaram a resolução para todas as questões; no entanto, existem outros meios de divulgação e de se manter no mercado.

Os jovens procuram inserir novas marcas; no entanto, às vezes não têm tanta orientação e menção de vendas positivas. Eles buscam ter o conhecimento dos seus produtos com o intuito de passar confiança aos seus consumidores e, quando perguntados sobre a má impressão com relação aos seus clientes, eles afirmam que isso não ocorre com frequência; mas quando isso ocorre, conseguem reverter, considerando um ponto positivo para o empreendimento. Os entrevistados relataram que não tiveram desavenças com os seus fornecedores, pois precisam manter uma boa convivência e a competitividade ativa.

Assim como as demais cidades de pequeno porte da Paraíba, Guarabira tem o centro urbano como principal polarizador da economia. As atividades econômicas da cidade são voltadas principalmente para o setor terciário e para a prestação de serviços, como por exemplo: educação; saúde; comércio composto por lojas; fábricas dos setores alimentícios, têxtil, calçadista e de rações; empresas privadas; shopping center etc. No que se refere aos estudos de Silva (2011), além do centro da cidade, outras áreas importantes para o desenvolvimento econômico são a feira livre, o mercado público, além dos distritos industriais e de educação etc.

O comércio informal da cidade vem crescendo nos últimos 10 anos, pois há trabalhadores exercendo diversas funções, lutando pela sobrevivência de suas famílias, além do número de empreendedores com suas pequenas empresas familiares ou em parcerias.

\section{Considerações finais}

Este estudo teve como objetivo geral analisar as competências dos jovens na cidade de Guarabira-PB através das habilidades desenvolvidas e das dificuldades enfrentadas por eles. Partindo desse pressuposto, formulou-se o problema de pesquisa: identificar quais são as competências empreendedoras que os jovens da cidade de Guarabira têm e quais são suas estratégias de sobrevivência no mercado?

Buscando responder a esse problema, observou-se que os jovens possuem habilidades pessoais, buscam por conhecimento, têm facilidade de comunicação com seus clientes, capacidade de manter a competitividade, o comprometimento para com os seus empreendimentos, ética e confiabilidade etc. Eles empreendem por desejarem ser donos de seus próprios negócios, como também para complementação de renda familiar. Além disso, o que impulsionam esses novos caminhos para a inserção no mercado é a falta de oportunidade de emprego em Guarabira, no que se refere à ausência de experiência e abertura de novos postos de trabalho.

Apesar desse despertar empreendedor, ainda existem brechas evidentes em suas competências, que evidenciam as possíveis falhas. Tais falhas remetem à má gestão de planejamento e a ausência de capacitação. Desse modo, sabese que se inserir no mercado de trabalho, muitas vezes, não é uma tarefa fácil, pois é necessário ter conhecimento em determinadas áreas como finanças, empreendedorismo e marketing, por exemplo. A ausência dessas competências é o que faz muitos empreendimentos não chegarem a dois anos de existência, indo à falência por não conseguir agregar valor aos seus empreendimentos.

Dessa forma, diante das competências levantadas nesse estudo, os participantes da pesquisa apresentaram mais desenvolvimento nas competências de oportunidade e de relacionamento. No que se refere à oportunidade, os entrevistados possuem a percepção de melhorar seus empreendimentos e de estarem aptos a identificar e desenvolver melhorias referentes aos objetivos da organização. Já em relação à competência de relacionamento, eles conseguem demonstrar uma boa imagem por meio de uma comunicação e vestimentas adequadas, vestimenta, passando confiança aos seus colaboradores, fornecedores e clientes; porém, eles têm dificuldades de resolver problemas do cotidiano, de curto e longo e prazos, por não terem um planejamento adequado. 
Nas demais competências, o nível de adequação foi menor. Nas competências conceituais, observou-se que os jovens empreendedores não possuem habilidades para avaliar todas as situações de risco e traçar um plano para cada problema, além de não gerenciarem suas rotinas de trabalho e de não usarem ferramentas de gestão financeira. Nas competências administrativas - que dizem respeito a como o empreendedor destina os seus recursos financeiros, tecnológicos e físicos -, observou-se que a maioria dos entrevistados não consegue fazer bom uso dos seus recursos financeiros por não possuírem fluxo de caixa para eventuais contratempos, além de não saberem avaliar o valor do investimento e de misturar as despesas pessoais com as despesas do negócio, o que impacta negativamente no planejamento de possíveis investimentos necessários para a organização.

Quanto às competências estratégicas, os empreendedores não estão preparados para mudanças e, consequentemente, não conseguem perceber situações emergenciais no ambiente de trabalho, a fim de não comprometer o andamento da organização. Com relação às competências de comprometimento, os entrevistados demonstraram compromisso e lealdade tanto com os colaboradores quanto para o empreendimento. No entanto, eles não fazem uso do plano de ação, esquecendo de suas metas.

Logo, diante das competências elencadas neste trabalho, pode-se compreender que esses jovens empreendedores carecem do desenvolvimento de competências que possam melhorar a performance de seus empreendimentos. Com relação às competências que eles não possuem, os entrevistados precisam saber administrar o tempo, fazendo uso correto de ferramentas que irão auxiliá-los no processo de gerenciamento. Ter conhecimento em finanças irá ajudá-los a entender como funciona os seus recursos financeiros, além do fluxo de caixa, suprindo as necessidades que venham a acontecer; fazer um bom plano de negócio para alcançarem as suas metas, além de ter noção de marketing, a fim de usarem corretamente as redes sociais; saber analisar os cenários com o intuito de lidar com as mudanças e agir quando necessário; focar nas metas profissionais, sem que as da vida pessoal os atrapalhem; e, por fim, fazer uma pesquisa dos produtos que mais vendem, antes de compor melhor o mix de vendas.

Um dos fatores que limitaram o presente estudo está relacionado à disponibilidade dos empreendedores para serem entrevistados no período de finalização desta etapa. Como proposta para estudos futuros, sugere-se que a pesquisa tenha continuidade para que os resultados possam ser abrangentes, com a utilização de métodos quantitativos que proporcionam um alcance maior de participantes para uma melhor compreensão das competências empreendedoras, não apenas para os jovens, mas também empreendedores de outras faixas etárias.

Dessa forma, a pesquisa poderá contribuir com os trabalhos já desenvolvidos sobre empreendedorismo jovem, tendo como panorama o interior do Estado da Paraíba. Sendo o primeiro trabalho realizado nessa temática na cidade de Guarabira, este servirá de base para outros pesquisadores que despertem interesse no tema. Este trabalho servirá também como fonte de informação para os jovens que participaram da pesquisa, no intuito de que compreendam a importância das competências empreendedoras em seus empreendimentos. De outro modo, esse estudo também aponta possíveis campos de ação para instituições de fomento às micro e pequenas empresas, no sentido de proporcionar o desenvolvimento de competências importantes para o desenvolvimento econômico e social da cidade de Guarabira.

\section{Referências}

ANDRADE, D. M.; LIMA, J. B e BORGES, A. F. Ações Empreendedoras em Empresas Familiares: Um Estudo Sob a Ótica de Oportunidades, Inovação e Aprendizagem. In: VIII Encontro de Estudos em Empreendedorismo e Gestão de Pequenas Empresa (EGEPE). Goiânia, p 1-17, 2014.

ANTONELLO, C. S.; BOFF, L. H. e colaboradores. Os novos horizontes da gestão: Aprendizagem organizacional e competências. Porto Alegre: Bookman, 2005, 222 p.

BARDIN, L. Análise de conteúdo. Lisboa: Edições, 1977, 70 p.

BARROS, A. A.; PEREIRA, C. M. M. A. Empreendedorismo e crescimento econômico: uma análise empírica. Revista de Administração Contemporânea. Curitiba, v.12, n.4, out./dez., 2008.

BRASIL. Lei $\mathbf{n}^{\mathbf{0}} \mathbf{1 2 . 8 5 2}$, de 5 de agosto de 2013. 
BRITO, A. M; PEREIRA, P. S; LINARD, A. P. Empreendedorismo. In: Instituo Federal de Educação, Ciência e Tecnologia do Ceará - IFCE, Juazeiro do Norte, Universidade federal de Santa Catarina para a e-TEC Brasil, 2013, 96.

BORGES, C, FILION, L. J, SIMARD, G. Jovens Empreendedores e o Processo de Criação de Empresas. Revista de administração, Vo 9, No 8, Edição Especial. pp. 1- 25, Nov./Dez. 2008,

CACCIAMALLI, M. C. Os ambulantes no carnatal: oportunidades de trabalho ou lazer?. In: Elaine Cristina Alves da C. Savalli. Revista Eletrônica Inter-legere, nº 03, 2008. pp. 01-10.

CONCEIÇÃO, O. S. Empreendedorismo: Perfil dos jovens empreendedores de Caraguatatuba. Monografia (Curso Técnico de Processos Gerenciais) - Instituo Federal de Educação, Ciência e Tecnologia de Caraguatatuba - IFSP, 2017, 50 p.

CHAER, G.; DINIZ, R. R. P. e RIBEIRO, E. A. A técnica do questionário na pesquisa educacional. Araxá: Evidência, vol. 7, n. 7, pp. 251-266, 2011

CHIAVENATO, I. Empreendedorismo: Dando asas ao espírito empreendedor. 4 ed. Barueri: Manole, 2012, $315 \mathrm{p}$.

COSTA, C. da. O empreendedor no Brasil. Administradores, [s.l.], 23 mar. 2009. Disponível em: $<$ http://www.administradores.com.br/artigos/as-caracteristicas- e- o-perfil-do-empreendedor/24327/>. Acesso em: $12 / 02 / 2019$

CUSTÓDIO, T. P. A importância do empreendedorismo como estratégia de negócio/Telma Padilha Custódio. Monografia (Curso de Administração) - Centro Universitário Católico Salesiano Auxilium UNISALESIANO, Lins-SP, 2011. 62 p.

DORNELAS, J. C. A Empreendedorismo: Transformando ideias em negócios. Rio de Janeiro: LTC, 2015.

Empreendedorismo. 2 ed., Rio de Janeiro: Campus, 2001.

Elsevier, 2007.

Empreendedorismo na prática: Mitos e verdades do empreendedor de sucesso Rio de Janeiro:

DRUCKER, P. F. Inovação e espírito empreendedor: prática e princípios. 10. ed. São Paulo: Pioneira Thomson, 2003, 378 p.

EVERTON JÚNIOR, A. MPE: Avanços importantes para as micro e pequenas empresas. Rio de janeiro: Confederação Nacional do Comércio de Bens, Serviços e Turismo, 2017, 98 p.

FILION, L. J. O planejamento do seu sistema de aprendizagem empresarial: Identifique uma visão e avalie o seu sistema de relações. Revista de Administração de Empresas, São Paulo, vol. 31, no 3, pp. 63-71, jul./ set 1991.

FILION. L. J.; DOLABELA, F.; e seus colaboradores. Boa idéia! E agora: plano de negócio, o caminho seguro para criar e gerenciar sua empresa. São Paulo: Cultura Editores Associados, 2000.

Global Entepreneurship Monitor - GEM. Empreendedorismo no Brasil: Relatório Executivo, 2017, 23 p.

GEM. Relatório Especial: O empreendedorismo e o mercado de trabalho, 2017, 58 p.

. GEM. Empreendedorismo no Brasil, 2016, 210 p.

. GEM. Relatório Executivo. 2015, 21 p.

. GEM. Empreendedorismo no Brasil. Curitiba, 2013, 174 p.

GODOY, A. S. Introdução à pesquisa qualitativa e suas possibilidades. Revista de Administração de Empresas, São Paulo, Vol.35, n² 2, pp. 57 - 63, 1995.

GLASER, B. G.; STRAUSS, A. L. The discovery of grounded theory: strategies for qualitative research. Chicago: Aldine Publishing Company, 1967.

GRANOVETTER, M. Economic action and social structure: The problem of embeddedness. American Journal of Sociology, Chicago, vol. 91, n. 3, p. 481-510, Nov. 1985. 
HENRIQUE, D. C; CUNHA, S. K. Metodologias, Recursos e Práticas Didático-Pedagógicas no Ensino de Empreendedorismo em Cursos de Graduação e Pós-Graduação Nacionais e Internacionais. In: Encontro da ANPAD, 2006, Salvador/BA, 2006.

HILLS, G., \& LAFORGE, R. W. (1996). Marketing and entrepreneurship. Chicago: University of Illinois.

Instituto Brasileiro de Geografia e Estatística - IBGE. Censo Demográfico. Paraíba: IBGE, 2015.

IBGE. Censo Demográfico. Paraíba: IBGE, 2010.

IBGE. Demografia das empresas e estatísticas de empreendedorismo. Paraíba: IBGE, 2016. Disponível em: <https://cidades.ibge.gov.br/brasil/pb/pesquisa/10088/76967?tipo=ranking>. Acesso em: $\underline{30 / 03 / 2019}$

JAIN, R. K. Entrepreneurial Competencies: A Meta-analysis and Comprehensive Conceptualization for Future Research. Vision, 15(2) 127-152, 2011.

LIU, J. Business failures and macroeconomic factors in the uk. Bulletin of economic research, n. 61, v. 1, 2009.

LEIRIA, A. M. L. As competências do empresário da empresa de pequeno porte: um breve estudo sobre um grupo de empresários vencedores do Prêmio Talentos Empreendedores na região metropolitana de Porto Alegre. Dissertação (Mestrado em Administração) - Porto Alegre, 2002, 70 p.

LENZI, F.C. Os empreendedores corporativos nas empresas de grande porte dos setores mecânico, metalúrgico e de material elétrico/comunicação em Santa Catarina: um estudo da associação entre tipos psicológicos e competências empreendedoras reconhecidas. Tese. Curso de Administração) - Faculdade de Economia, Administração e Contabilidade, 2008, 126 p.

LIZOTE, S.A.; VERDINELLI, M.A. Competências empreendedoras: um estudo com funcionários administrativos de uma empresa do ramo alimentício. Revista Pensamento Contemporâneo em Administração, Rio de Janeiro, vol. 8 n 1, pp. 164-182, 2014.

KIVRAK, S.; ARSLAN, G. Factors causing construction company failure. Building Abroad, 2008, oct., p. 297 305.

MAHAMID, I. Factors affecting contractor's business failure: contractors' perspective. Engineering, Construction and Architectural Management. Emerald insignt, vol. 19 n. 3, p. 269-285, 2012.

MAMEDE, MI de B.; MOREIRA, M. Z. Perfil de competências empreendedoras dos investidores Portugueses e Brasileiros: Um estudo comparativo na rede hoteleira do Ceará. Anais do XXIX Encontro Anual da Associação de Pós-Graduação e Pesquisa em Administração, Brasília, 2005.

McCRACKEN, G. The long interview: qualitative research methods series. Newburn Park, CA: Sage Publications, 1988.

MAN, T. W. Y.; LAU, T. (2000, September). Entrepreneurial competencies of SME owner/manager in the Hong Kong services sector: a qualitative analysis. Journal of Enterprising Culture, 8 (3), 235-254.

MAN, Thomas WY; LAU, Theresa. Entrepreneurial competencies of SME owner/managers in the Hong Kong services sector: A qualitative analysis. Journal of Enterprising Culture, v. 8, n. 03, p. 235-254, 2000.

MANZINI, E. J.; DO TANAKA, E. O que os empregadores pensam sobre o trabalho da pessoa com deficiência. Revista Brasileira de Educação Especial, São Paulo, vol. 11, n. 2, p. 273-294, 2005. Disponível em: <http://www.apaenet.org.br/images/apostilas/oque_empregadores_pensam_.pdf>. Acesso em: 02/04/2019.

NASCIMENTO, M. et al. Fatores determinantes da mortalidade de micro e pequenas empresas da região metropolitana de Florianópolis sob a ótica do contador. Revista Eletrônica de Estratégia \& Negócios, vol. 6, n. 2, p. p. 244-283, 2013.

Mintzberg, H., \& Quinn, J. B. O processo da estratégia. 2. ed., Porto Alegre: Bookman, 2001.

PAIVA JÚNIOR, F. G.; LEÃO, A. L. M. de S.; MELLO, S. C. B. Competências empreendedoras em comportamentos de dirigentes de êxito socialmente reconhecido. In: Encontro da Associação Nacional dos Programas de Pós-graduação em Administração, 27, Atibaia/SP, 2003. 
PAIVA JÚNIOR, F. G.; GUERRA, J. R. F.; OLIVEIRA, M. A. F. de; et al. A contribuição das competências empreendedoras para a formação de dirigentes em sistemas de incubação. In: Encontro Nacional de Estudos da Engenharia de Produção - ENEGEPE, Fortaleza-CE, pp. 47-69, 2006.

Proposta de Ementa à Constituição - PEC. Disponível em: $<$ https://www2.camara.leg.br/camaranoticias/noticias/ADMINISTRACAO-PUBLICA/149638-PEC-DAJUVENTUDE-INICIA-MARCO-LEGAL-DE-POLITICAS-PARA-PESSOAS-ENTRE-15-E-29-

ANOS.html> Acesso em: 13/04/2019

POLITIS, D. The process of entrepreneurial learning: A conceptual framework. Entrepreneurship Theory and Practice, p. 399-424, July 2005.

PRADANOF, C. C. e FREITAS, E. C. de. Metodologia do trabalho científico: Métodos e Técnicas da Pesquisa e do Trabalho Acadêmico. 2. Ed. Universidade de FEEVALE, Novo Hamburgo - RS, 2013, 277 p.

RAYOL, M.K.B. A importância do plano de negócio para o sucesso do empreendimento. Disponível em: http://peritocontador.com.br/wp-content/uploads/2015/05/Marcus-Kleber-Bentes-Rayol-AImport $\%$ C $3 \%$ A2ncia-do-Plano-de-Neg $\%$ C3\%B3cio-para-o-Sucesso-do-Empreendimento.pdf. Acesso em: $14 / 06 / 2019$

Revista Endeavor Brasil. Empreendedores brasileiros: Perfis e percepções, 2013, 102 p.

Estatísticas do empreendedorismo - 2005. Disponível em: <https://endeavor.org.br/pesquisas/>. Acesso em: 21/03/2019.

RIVERIN, N.; JEAN, N. (2005). L'entrepreneuriat chez les jeunes du Québec: état de la situation. Relatório de pesquisa. Disponível em: <http://www.hec.ca/entrepreneuriat>.

REIS, Z. R. Micro e pequenas empresas: a importância de aprender a empreender. Fundação Getulio Vargas (FGV). Escola Brasileira de Administração Pública e de Empresas. Centro de Formação Acadêmica e Pesquisa Curso de Mestrado em Gestão Empresarial - Minter. RJ, 2006.

RING, P. S. \& VAN DE VEN, A. H. (1994) - Developmental processes of cooperative interorganizational relationships. Academy of Management Review, vol. 19, n.1, p. 90-118.

RIBEIRO, L.; CAMPOS, L. C. Perfil e motivação dos jovens empreendedores em Belém do Pará. Revista de Administração e Contabilidade da Faculdade Estácio do Pará - Belém. vol. 4, n. 8, p. 227-244, dez 2017, ISSN 2358-1948.

SANTINI, et. al. Fatores de mortalidade em micro e pequenas empresas: um estudo na região central do rio grande do sul. Revista Eletrônica de Estratégia e Negócio. Florianópolis, Vol. 8, n 1, 145-164, 2015.

SARKAR, Soumodip. $\mathbf{O}$ empreendedor inovador: faça diferente e conquiste seu espaço no mercado. 1. ed., Rio de Janeiro: Elsevier, 2008, 286 p.

Serviço Brasileiro de Apoio a Micro e Pequenas Empresa - SEBRAE. Estudo da mortalidade das empresas paulistas. Disponível em: < http://www.sebraesp.com.br/arquivos_site >. 2012. Acesso: 12/03/2019

SEBRAE. O empreendedorismo e o mercado de trabalho. Brasília: SEBRAE, 2017.

SEBRAE. Coleção, Estudos e Pesquisa: Taxa de Sobrevivência das Empresas do Brasil, 2011, 30 p.

SEBRAE. Participação das Micro e Pesquinas Empresa na economia brasileira, 2014, 108 p.

SEBRAE. Como elaborar um Plano de Negócios. Brasilia: SEBRAE, 2013.

SILVA, M. G. O comércio informal na avenida Dom Pedro II na cidade de Guarabira-PB. Monografia (Curso de Geografia) - Universidade Estadual da Paraíba, Guarabira, 2011, 41 p.

Sistema Firjan. Jovens Empresários Empreendedores: Valores, Crenças e Relação com o trabalho, 2016, 27 p.

ZUINI, Priscila. Site da Revista Pequenas Empresas \& Grandes Negócios. 2016. Disponível em: $<$ http://revistapegn.globo.com/Videos/prisciladecifra/noticia/2016/03/empreenderporoportunidade-ounecessidade-entenda-diferenca.html>. Acesso em: 30/02/2019. 